Original Article

\title{
Women with type 2 diabetes mellitus: sociodemographic profile, biometrics and health*
}

\author{
Mulheres com Diabetes mellitus tipo 2: perfil sociodemográfico, biométrico e de saúde
}

Mujeres con Diabetes mellitus tipo 2: perfil sociodemográfico, biométrico y de salud

\author{
Juliana Cristina Lessmann ${ }^{1}$, Denise Maria Guerreiro Vieira da Silva ${ }^{2}$, Silvia \\ Modesto Nassar ${ }^{3}$
}

\begin{abstract}
Objective: To understand the profile of women with type 2 diabetes mellitus, focusing on sociodemographic factors, biometrics and health. Methods: A quantitative, transversal, prospective study with a stratified random sample, conducted in Florianópolis/SC with 147 women by means of home visits between April and August of 2009. Results: The women had a mean age of 66 years, presented elevated indexes of body weight, capillary glycemia and abdominal circumference, along with a low adherence to non-pharmacological treatment. A low educational level was associated with inadequate glycemic control, no physical activity, and inadequacy of the diet. Conclusions: Women with lower education constitute a vulnerable group and require health interventions congruent with their capacities of understanding and possibilities of adaptation to treatment.
\end{abstract}

Keywords: Diabetes mellitus type 2/epidemiology; Women; Nursing; Chronic disease

\section{RESUMO}

Objetivo: Conhecer o perfil de mulheres com Diabetes mellitus tipo 2, enfocando fatores sociodemográficos, biométricos e de saúde. Métodos: Estudo de abordagem quantitativa, transversal, prospectivo com amostra estratificada aleatória, desenvolvido em Florianópolis/SC com 147 mulheres por meio de visitas domiciliares entre abril e agosto de 2009. Resultados: As mulheres tinham idade média de 66 anos, apresentaram elevados índices de massa corporal, glicemia capilar e circunferência abdominal, além de baixa adesão ao tratamento não medicamentoso. A baixa escolaridade associou-se ao controle inadequado da glicemia, não realização de atividade física e inadequação da dieta. Conclusões: Mulheres com baixa escolaridade constituem grupo vulnerável e necessitam de intervenções em saúde congruentes com suas capacidades de compreensão e possibilidades de adaptação ao tratamento.

Descritores: Diabetes mellitus tipo 2/epidemiologia; Mulheres; Enfermagem; Doença crônica

\section{RESUMEN}

Objetivo: Conocer el perfil de mujeres con Diabetes mellitus tipo 2, enfocando factores sociodemográficos, biométricos y de salud. Métodos: Estudio de abordaje cuantitativo, transversal, prospectivo realizado con una muestra estratificada aleatoria, desarrollado en Florianópolis/ SC con 147 mujeres por medio de visitas domiciliarias entre abril y agosto del 2009. Resultados: Las mujeres tenían edad promedio de 66 años, presentaron elevados índices de masa corporal, glicemia capilar y circunferencia abdominal, además de baja adhesión al tratamiento no medicamentoso. La baja escolaridad se asoció al control inadecuado de la glicemia, no realización de actividad física e inadecuación de la dieta. Conclusiones: Las mujeres con baja escolaridad constituyen un grupo vulnerable y necesitan intervenciones en salud congruentes con sus capacidades de comprensión y posibilidades de adaptación al tratamiento.

Descriptores: Diabetes mellitus tipo 2/epidemiologia; Mujeres; Enfermería; Enfermedad crónica

\footnotetext{
* Study held in the Federal University of Santa Catarina - UFSC - Florianópolis (SC), Brazil.

${ }^{1}$ Post graduate student (Phd), Post Graduation Program in Nursing, Federal, University of Santa Catarina - UFSC - Florianópolis (SC), Brazil. Scholarship by CAPES/REUNI.

${ }^{2}$ PhD in Nursing, Associate Professor of the Post Graduation Program in Nursing, Federal University of Santa Catarina - UFSC - Florianópolis (SC), Brazil.

${ }^{3} \mathrm{PhD}$ in Electrical Engineering, Titular Professor of the Statistics Department, Federal University of Santa Catarina - UFSC - Florianópolis (SC), Brazil.
} 


\section{INTRODUCTION}

Diabetes mellitus type 2 (T2DM) is recognized as a set of metabolic and endocrine disorders which lead to an increased resistance to insulin, that incur specific demands of treatment, care and control, and may also imply on intense adaptations to everyday lives of people. ${ }^{(1,2)}$.

The control of T2DM congregates the adherence to a drug therapy, the adoption of a diet that restricts carbohydrates, lipids and sugar, all combined with physical activity ${ }^{(3)}$ aiming to improve the cardiovascular function and to prevent the accumulation or even the decrease of body fat ${ }^{(4)}$. The adipose tissue has intrinsic resistance to the action of insulin to mediate the glucose transport to the intracellular medium ${ }^{(5)}$, and people with T2DM who are overweight present higher difficulty with glycemic control, in several cases needing the association of more than one oral medication or even the use of insulin for the treatment of the condition (T2DM).

Another important component for the control of T2DM is the capillary glucose measurement, a fast and efficient method to verify the glucose in peripheral whole blood. This is an option of easy access, available throughout all Public Health Centers (Centros de Saúde-CS) and that can also be used in domicile. In Brazil the reference values for postprandial glycemia after 1.30 to 2 hours of food restriction vary between 80 to $160 \mathrm{mg} / \mathrm{L}^{(2)}$ so, levels ranging from 161 to $180 \mathrm{mg} / \mathrm{L}$ are considered acceptable and above $180 \mathrm{mg} / \mathrm{L}$ is considered as inadequate T2DM control ${ }^{(6)}$. An American Association also recommends the levels of postprandial glycemia in adults with around 2 hours of food restrictions to be lower than $180 \mathrm{mg} / \mathrm{L}^{(3)}$.

The care and management of the T2DM consist in a global challenge for the health actions focused on issues of prevention, cure and control ${ }^{(2-3,7,8)}$. This pathology is a precursor to other health problems and may result in complications, especially on the cardiovascular system, kidneys, nerves and eyes ${ }^{(2)}$. The control of T2DM and the need for habits and routine changes, especially related to meals and medication, can provoke a great impact on the lives of people with $\mathrm{T} 2 \mathrm{DM}^{(2)}$. Thus, for the establishment of health and nursing actions in accordance with the needs of people affected by T2DM, it becomes important to know their characteristics, peculiarities and behavior when it comes to treatment/care, by subsidizing health interventions that are more effective and capable of increasing the adherence to therapy.

Given the above, this research was guided by the following inquiry: What are the socio-demographic and biometric characteristics, the life and health habits of the women with T2DM? Therefore, the objective was to know the profile of women with T2DM emphasizing socio-demographic, biometric and health issues.

\section{METHODS}

This is a study of quantitative, transversal and prospective approach, with a stratified random sample that integrates the thesis of a Master's degree $\mathrm{e}^{(9)}$. It was developed in the city of Florianópolis, that has primary care integrated with the Unified Health System (Sistema Único de Saúde - SUS), and organized in accordance with the dynamic of services regionalization, distributed into five Regional Health sections ${ }^{(10)}$. The data collection was performed in one of the Regional Health Centers: Continent, East, South and Central. The Health Centers selected (Centros de Saúde - CS) were the ones with computerized data information of the local population, and that also allowed access to the records of people with Diabetes.

The population of the research was composed of 241 women with T2DM registered at the four CS and the sample size was calculated with a confidence interval (CI) of $95 \%$, reaching a total of 147 women studied. The sample (n) of the survey was stratified according to the female population with T2DM registered at each CS. To this end, the website SEstatNet ${ } /$ UFSC was used for the teaching of statistics ${ }^{(11)}$.

This computational online tool ${ }^{(11)}$ also provided the numeric routine with equiprobable distribution for the selection of the study participants who where previously listed in accordance with the stratum, in alphabetical order by first name and in ascending numbers.

In the study the criteria for inclusion of women were: having been diagnosed with T2DM for over one year, to be over 18 years old and to keep food restrictions between 90 to 120 minutes prior to the interview. The criteria adopted for exclusion were: impossibility of location after the second attempt by telephone/ in person or unwillingness to take part in the study.

The data collection happened between April and August/2009 in the women's domicile and the interviews were made by a Master's student and four previously trained nursing students who used collection material, forms and standardized procedures.

During the interviews at home, socio-demographic information about lifestyle was requested and biometric variables were verified, such as stature, weight, abdominal circumference, blood pressure and postprandial capillary glucose. The measurement of systolic (SBP) and diastolic (DBP) blood pressure was taken 
in accordance with the standardized protocol $^{(12)}$, as well as the assessments of capillary glucose levels ${ }^{(2,3,6)}$.

For the biometric data evaluation, aneroid sphygmomanometers and stethoscopes approved by the National Institute of Metrology were used as well as a soft tape measure, a semi-malleable metric tape measure graduated in centimeters $(\mathrm{cm})$, a portable digital scale with blood pressure sensor and maximum capacity of $150 \mathrm{~kg}$ divided in every 100 grams. Also a glucose meter that provides the glucose result in five seconds with previously tested batches.

The data collected were input in a file of the program Excel $\AA$ by Microsoft $\AA$, distributed on a spreadsheet in accordance with the chosen variables and exported to the computational online tool SEstatNet $\mathbb{R} / \mathrm{UFSC}^{(11)}$.

A descriptive statistic was performed (mean, median, standard deviation, minimum range, maximum and quartiles) for the continuous and discreet quantitative variables. With these variables the test Spearman correlation was also performed as the data did not show normality in the distribution. As for nominal and ordinal qualitative variables, analysis of absolute, relative and accumulated frequency was made. The chi square multivariate test was also performed for categorical correlations between the variable adherences to the prescribed diet, physical activity practice, HGT realization and education (stratified into two categories: lower and/or equal to the fourth grade of Elementary school and higher than the fourth grade of Elementary School).

During the process of data collection and analysis, the ethical aspects were ensured in order to guarantee confidentiality and impartiality, as well as the signature of a Term of Consent by all the participants. The research was submitted to the Ethical Committee in Research of the institution where it was developed and approved without any restrictions in case number 398/08. The study received financial support from the National Council of Scientific and Technological Development under the announcement number 57/2008 - Gender Relationships, Women and Feminism.

\section{RESULTS}

The women with T2DM surveyed were 66 years old on average, with a standard deviation (SD) of 10.8 years and reported 10.4 years (SD 8.4 years) as the average time of discovery of the disease. The family income indicated by 94 women was equivalent to $\mathrm{R} \$$ $1.791,00$ (on average). The other characteristics are presented in the data of Table 1.
Table 1. Social characteristics of women with T2DM, Florianópolis, 2009

\begin{tabular}{|c|c|}
\hline Demographic characteristics & $\mathrm{n}(\%)$ \\
\hline \multicolumn{2}{|l|}{ Race } \\
\hline White & $121(82.32)$ \\
\hline Black & $13(8.84)$ \\
\hline Brown & $13(8.84)$ \\
\hline \multicolumn{2}{|l|}{ Marital status } \\
\hline Married/Civil union & $68(46.26)$ \\
\hline Widow & $48(32.65)$ \\
\hline Divorced & $21(14.29)$ \\
\hline Single & $10(6.80)$ \\
\hline \multicolumn{2}{|l|}{ Religion } \\
\hline Catholic & $111(75.51)$ \\
\hline Protestant & $21(14.29)$ \\
\hline Spiritist & $9(6.12)$ \\
\hline Others & $6(4.08)$ \\
\hline \multicolumn{2}{|l|}{ Type of domicile } \\
\hline Brickwork & $122(82.99)$ \\
\hline Wood & $16(10.88)$ \\
\hline Mixed & $9(6.13)$ \\
\hline \multicolumn{2}{|l|}{ Home ownership } \\
\hline Own & $118(80.27)$ \\
\hline Rented & $21(14.29$ \\
\hline Ceded/borrowed & $8(5.44)$ \\
\hline \multicolumn{2}{|l|}{ Labor activity } \\
\hline Retired & $90(61.22)$ \\
\hline Economically active & $42(28.58)$ \\
\hline Economically inactive & $15(10.20)$ \\
\hline
\end{tabular}

This study showed that $55.10 \%$ of women were not literate or have studied only until the fourth grade of Elementary School (Table 2), showing a majority with low level of education.

Table 2. Level of education of women with T2DM. Florianópolis, 2009

\begin{tabular}{lc}
\hline Level of education & $\mathbf{n}(\mathbf{\%})$ \\
\hline Illiterate & $11(7.48)$ \\
Incomplete elementary school & \\
$1^{\text {st }}$ to $4^{\text {th }}$ grade & $70(47.62)$ \\
$5^{\text {th }}$ to $7^{\text {th }}$ grade & $18(12.24)$ \\
Complete elementary school & $7(4.76)$ \\
Incomplete secondary school & $6(4.08)$ \\
Complete secondary school & $24(16.34)$ \\
Incomplete higher education & $2(1.36)$ \\
Complete higher education & $6(4.08)$ \\
Post graduation & $3(2.04)$ \\
\hline
\end{tabular}


In order to assess the metabolic control of the survey participants, an analysis of psychosocial, health and lifestyle data was made, as well as of bio- metric values, aiming to elucidate the care conditions and adherence to T2DM treatment, as described on Table 3:

Table 3 - Biometric characteristics of women with T2DM, Florianópolis, 2009

\begin{tabular}{lcccccc}
\hline Biometric variables & Mean & SD & Minimum & $\mathbf{1}^{\text {st }}$ Quartile & $3^{\text {rd }}$ Quartile & Maximum \\
\hline Glycemia(mg/dL) & 186.77 & 77.67 & 85.00 & 132.00 & 234.00 & 456.00 \\
SBP (mmHg) & 133.00 & 20.00 & 90.00 & 120.00 & 140.00 & 220.00 \\
DBP (mmHg) & 80.00 & 10.00 & 55.00 & 70.00 & 80.00 & 120.00 \\
BMI (Kg/m2) & 29.13 & 5.62 & 18.10 & 24.79 & 32.89 & 45.71 \\
WC (cm) & 100.60 & 13.02 & 74.00 & 92.00 & 108.00 & 141.00 \\
\hline
\end{tabular}

Legend: SD: Standard deviation; SBP: Systolic blood pressure; DBP: Diastolic blood pressure; BMI: Body mass index; WC: Waist circumference.

The test correlation of Spearman was used to investigate the relationship between BMI and the variables age, glycemia, length of time that the woman has
T2DM and waist circumference, and the only link of statistical significance observed was between BMI and waist circumference (Table 4).

Table 4. Statistical tests between biometric variables, Florianópolis, 2009

\begin{tabular}{lcc}
\hline Biometric variables & Correlation of Spearman & P-value \\
\hline BMI X age & -0.0121 & 0.4420 \\
BMI X glycemia & 0.0152 & 0.4273 \\
BMI X time with T2DM & 0.0455 & 0.2918 \\
BMI X abdominal circumference & 0.8355 & 0.000001 \\
\hline
\end{tabular}

When investigating the causes for high values of BMI and abdominal circumference, it was observed that regarding lifestyle and health habits, only $38.78 \%$ of women with T2DM practiced physical activities. Among those engaged in physical activities, the average number of practice per week was 3.78 times (SD 1.88) with the median equivalent to three times a week. As for the average duration of activity per day, it was of 58 minutes (SD 23), with a maximum of 120 and a minimum of 10 minutes.

Another important factor for the T2DM control was the monitoring and adherence to dietary regimens prescribed by a physician/nutritionist that, in most cases, limit the intake of carbohydrates and lipids, leading to the maintenance of blood glucose levels as well as to a body weight that is compatible with the normality standards ${ }^{(2)}$. When questioned about maintaining the diet, $55.78 \%$ reported not to be properly following the dietary recommendations, $20.41 \%$ affirmed following the diet in most of the times and only $23.81 \%$ reported to always follow the recommended diet.

It was found that the average time of the participants' last doctor appointment was 2.2 months (SD 2.3). Also, that only $23(15.64 \%)$ women affirmed to have nursing appointments and, among these, just 16 were able to inform the period of their last consultation which had an average time of 3.1 months (SD 3.8). Regarding the use of medication, $75.51 \%$ of the women with T2DM used only oral hypoglycemic agents, $14.97 \%$ used just insulin and 9.52\% took insulin associated with oral hypoglycemic agents. Another important factor related to the medication use was that $87.07 \%$ of women with T2DM also used other prescribed drugs for the treatment of different pathologies.

Regarding the site where the glucose measurement was done, $60.55 \%$ of the women informed they did it at Health Centers, $28.57 \%$ did it at home, $5.44 \%$ went to a clinical analysis laboratory for the measurement and $5.44 \%$ did it elsewhere.

The frequency of the capillary glucose test (also called hemo glucose test, HGT) shows that $12.93 \%$ of the women had a daily control, $19.73 \%$ did a weekly control, $11.56 \%$ did the test every 15 days, $25.85 \%$ did a monthly control, $21.77 \%$ did the HGT with intervals of two to six months and $8.16 \%$ did the HGT only once a year.

In order to identify the association among the following variables; adherence to the prescribed diet, physical activity practice, realization of the HGT and education, an analysis of multiple correspondence was 
made and it was possible to identify the total of the data inertia ${ }^{(13)}$, equivalent to $83.59 \%$ in three dimensions.

Thus, with this figure, it became evident the strong association among the tested variables, leading to the conclusion that the women who studied until the fourth grade of Elementary school or less were the ones that presented the lowest frequency in monitoring the capillary glucose, the lowest adherence to the prescribed diet and practiced physical activities with not enough frequency or did not practice at all. Accordingly, it was possible to infer that women with education higher than the fourth grade of Elementary school were the ones with the best monitoring of the glucose levels and the highest adherence to the T2DM treatment.

\section{DISCUSSION}

The average age of the participants was similar to the ones on other studies ${ }^{(14-16)}$, suggesting that the T2DM is usually discovered around the age of 50 years. The prevalence of married women and widows, as well as retirees was inherent to the age group where they belonged. The average age of the respondents indicated that the majority was elderly; thus it was possible to observe that financial stability, as well as the result of labor during all adulthood reflected the kind of housing and the domicile ownership.

As for the race, the occurrence of $\mathrm{T} 2 \mathrm{DM}$ in the majority of white women corroborated one research that showed this disease affects $67 \%$ of white people ${ }^{(16)}$ and another one that pointed the same occurrence on $81 \%{ }^{(8)}$, both held in the South region of Brazil.

When assessing the biometric data of the participant women it was possible to observe an expressive percentage showing capillary glucose levels above the expected $(42.18 \%)$, even though all of them affirmed to be taking medication for DM control.

It was also found that the average BMI was equivalent to overweight $(29.13 \mathrm{Kg} / \mathrm{m} 2 \mathrm{SD} 5.62)$. Therefore it became evident that only $25 \%$ of the women surveyed had the weight within the normality zone, that $50 \%$ presented overweight and that $25 \%$ had some degree of obesity ${ }^{(2)}$. It was still observed that these women had accumulation of visceral fat, presenting abdominal circumference equivalent to $100.6 \mathrm{~cm}$ (SD13.02), being way above the maximum value recommended for wom$\mathrm{en}^{(2)}$, of $88 \mathrm{~cm}$. The obesity accompanied by visceral fat is an important risk factor for cardiovascular disease, especially when associated with $\mathrm{DM}{ }^{(15)}$.

The above findings seem to be potentially related to the weak adherence of these women to non-pharmacological treatment, as the majority did not adopt the diet $(55.78 \%)$ nor exercised $(61.22 \%)$, corroborating a survey ${ }^{(17)}$ which showed that around $50 \%$ of the people with DM did not change their lifestyle habits to control the disease. Some studies on adherence to treatment conducted in Brazil showed higher adherence rates, such as the study ${ }^{(18)}$ which demonstrated that the non-adherence to non-pharmacological treatment was of only $9.15 \%$ and the survey ${ }^{(19)}$ in which the subjects reported high adherence to the prescribed treatment. But it is worth to mention that the studies above-cited were conducted with convenience samples composed of people with T2DM that attended coexistence groups or that had regular medical appointments.

In contrast, with the women studied there was total adherence to the medication treatment $(100 \%)$ and to the health consultations with a physician, showing the priority of the treatment is focused on medication therapy and may be motivated by the culture of medicalization of health.

The nurses, with a prominent role in health education, were of restricted participation on the health care of women interviewed as they (nurses) have been mentioned by only $15.64 \%$ of them.

These characteristics express the need to intensify the health actions aimed at raising the awareness on the importance of treatment adherence as a means of promoting wellbeing and quality of life and reduction/prevention of comorbidities. Researchers ${ }^{(20)}$ add it is necessary to implement actions of education in health with services of attention to people with T2DM, since many know little about the care and treatment to control the disease. Therefore the active participation of the user in the health care system should be mediated by the dialogue and exchange of knowledge, having the nurse as a pillar for motivating actions in health education and group socialization ${ }^{(21)}$.

Another aspect of the T2DM control regards the capillary glucose level measurement thus it is recommended that people with T2DM who use oral medication perform the test at least once or twice a week ${ }^{(1)}$. People with T2DM who use insulin though, should perform three capillary glucose tests a day at different times ${ }^{(3)}$. The Ministry of Health does not establish an ideal frequency for capillary glucose testing for people with T2DM but affirms that a regular measurement provides adequacy of the therapeutic $^{(2,6)}$. Evaluating the data using the parameters described above it can be observed that a few women adapt to the recommended control. Hence, when extending the temporal range of glucose measurement for 30 days and considering that most women visit the Health Centers for control as the free medication is distributed every 30 days, it can be seen that $70.07 \%$ perform the HGT in this temporal range.

The results of this study showed that the women surveyed experience a necessity of specific care for the T2DM that is not always followed, particularly by women with lower education, which reinforces the need 
for an integral and individualized care that is committed to the elaboration of strategies for higher therapeutic adherence ${ }^{(1,6,17,22)}$.

\section{CONCLUSIONS}

This study showed that the majority of the participants had low education, a fact that can influence on adherence to proposed treatments and on the prevalence of conduct inadequacies related to the non-pharmacological care of T2DM.

\section{REFERENCES}

1. Sociedade Brasileira de Diabetes. Diretrizes da Sociedade Brasileira de Diabetes. Rio de Janeiro: Sociedade Brasileira de Diabetes; 2008.

2. Brasil. Ministério da Saúde. Secretaria de Atenção à Saúde. Departamento de Atenção Básica. Diabetes mellitus. Brasília: Ministério da Saúde; 2006. 56 p. (Cadernos de Atenção Básica; 16).

3. American Diabetes Association. Standards of medical care in diabetes--2010. Diabetes Care. 2010; 33 Suppl 1: S11-61.

4. Villas Boas LC, Foss MC, Freitas MC, Torres HC, Monteiro LZ, Pace AE. [Adherence to diet and exercise among people with diabetes mellitus]. Texto \& Contexto Enferm. 2011; 20(2):272-9. Portuguese.

5. Rana JS, Li TY, Manson JE, Hu FB. Adiposity compared with physical inactivity and risk of type 2 diabetes in women. Diabetes Care. 2007; 30(1): 53-8.

6. Brasil. Ministério da Saúde. Manual de hipertensão arterial e Diabetes mellitus. Brasília: Ministério da Saúde; 2002.

7. Samuel-Hodge CD, Headen SW, Skelly AH, Ingram AF, Keyserling TC, Jackson EJ, et al. Influences on day-to-day self-management of type 2 diabetes among African-American women: spirituality, the multi-caregiver role, and other social context factors. Diabetes Care. 2000; 23(7): 928-33.

8. Dode MA, Assunção MC, Valle NC. [Coverage, focus, risk factors associated with participation, and linkage to the National Campaign for Diabetes Detection in a city in Southern Brazil]. Cad Saúde Pública.2007; 23(8):1877-85. Portuguese.

9. Lessmann JC. Estresse em mulheres com Diabetes mellitus tipo 2 [dissertação]. Florianópolis: Universidade Federal de Santa Catarina; 2009.

10. Prefeitura Municipal de Florianópolis. Sistema de Informação da Atenção Básica [Internet]. [citado 2011 Dez 20]. Disponível em: http://www.pmf.sc.gov.br/entidades/saude/ index.php? $\mathrm{cms}=$ siab\&menu $=5$

11. Nassar SM, Wronscki VR, Ohira M. SEstatNet - Sistema Especialista para o Ensino de Estatística na Web [Internet]. Florianópolis: Universidade Federal de Santa Catarina; 2011 [atualizada em 2011 Dez 20; [citado 2009 Jan 20]. Disponível em: http://www.sestatnet.ufsc.br
It can be inferred that the low adherence to non pharmacological therapies may be a reflection of the social, economic, gender and family context conditions of women with T2DM.

Therefore, women with T2DM constitute a group vulnerable to developing health aggravations due to the low adherence to therapeutic and control of the disease, fact that expresses the relevance and demand that the health services and nurses expand the development of strategies to modify these profiles.

12. Sociedade Brasileira de Cardiologia-SBC; Sociedade Brasileira de Hipertensão-SBH; Sociedade Brasileira de NefrologiaSBN. [V Brazilian Guidelines in Arterial Hypertension]. Arq Bras Cardiol. 2007; 89(3):e24-79. Portuguese.

13. Johnson RA, Wichern DW. Applied multivariate statistical analysis. 4th ed. Upper Saddle River (NJ): Prentice Hill; 1998.

14. Torres HC, Souza ER, Lima MH, Bodstein RC. Educational intervention for self-care of individuals with diabetes mellitus. Acta Paul Enferm. 2011; 24(4):514-9.

15. Oliveira DS, Tannus LR, Matheus AS, Corrêa FH, Cobas R, Cunha EF, et al. Evaluation of cardiovascular risk according to Framingham criteria in patients with type 2 diabetes. Arq Bras Endocrinol Metab. 2007; 51(2):268-74.

16. Picon PX, Zanatta CM, Gerchman F, Zelmanovitz T, Gross JL, Canani LH. [Analysis of the criteria used for the definition of metabolic syndrome in patients with type 2 Diabetes mellitus] Arq Bras Endocrinol Metab. 2006; 50(2):264-70.

17. Delamater AM. Improving patient adherence. Clin Diabetes. 2006; 24(2):71-7.

18. Assunção TS, Ursine PG. [A study of factors associated to non-pharmacological treatment delivered by the Family Health Program in Ventosa, Belo Horizonte, to carriers of Diabetes mellitus]. Ciênc Saúde Coletiva. 2008; 13 Suppl 2:2189-97. Portuguese.

19. Silva I, Pais-Ribeiro J, Cardoso H. Diabetes mellitus treatment adherence: The relevance of demographic and clinical characteristics. Referência [internet]. 2006 [cited 2011 Dec 20]; 2(2):33-41. Available in: http:/ / repositorio-aberto.up.pt/ bitstream/10216/5525/2/31601.pdf

20. Troncoso PC, Sotomayor CM, Ruiz HF, Zúñiga TC.[Interpretation of the knowledge about type 2 diabetes and compliance to dietotherapy among elderly living in rural areas suffering from this disease]. Rev Chil Nutr. 2009; 35(4): 421-6. Spanish.

21. Francioni FF, Silva DG. [The process of people with Diabetes mellitus living healthful through a living group]. Texto \& Contexto Enferm. 2007; 16(1):105-11. Portuguese.

22. Lessmann JC, Silva DM, Nassar SM. [Stress in women with type-2 Diabetes mellitus]. Rev Bras Enferm. 2011; 64(3):4516. Portuguese. 